\title{
Nasal delivery of nanosuspension-based mucoadhesive formulation with improved bioavailability of loratadine: Preparation, characterization, and in vivo evaluation
}

\author{
Areen Alshweiat ${ }^{\mathrm{a}, \mathrm{b}, *}$, IIdikó Csóka ${ }^{\mathrm{a}}$, Ferenc Tömösi ${ }^{\mathrm{c}}$, Tamás Janáky ${ }^{\mathrm{c}}$, Anita Kovács ${ }^{\mathrm{a}}$, \\ Róbert Gáspár ${ }^{\mathrm{d}}$, Anita Sztojkov-Ivanov ${ }^{\mathrm{e}}$, Eszter Ducza ${ }^{\mathrm{e}}$, Árpád Márki ${ }^{\mathrm{f}}$, Piroska Szabó-Révésza ${ }^{\mathrm{a}}$, \\ Rita Ambrus, ${ }^{\mathrm{a}, *}$ \\ ${ }^{a}$ Faculty of Pharmacy, Interdisciplinary Excellence Centre, Institute of Pharmaceutical Technology and Regulatory Affairs, University of Szeged, Eötvös u. 6., H-6720 \\ Szeged, Hungary \\ ${ }^{\mathrm{b}}$ Faculty of Pharmaceutical Sciences, The Hashemite University, 13133 Zarqa, Jordan \\ ${ }^{\mathrm{c}}$ Department of Medical Chemistry, Faculty of Medicine, University of Szeged, Dóm tér 8, H-6720 Szeged, Hungary \\ ${ }^{\mathrm{d}}$ Department of Pharmacology and Pharmacotherapy, University of Szeged, Dóm tér 12, H-6720 Szeged, Hungary \\ ${ }^{\mathrm{e}}$ Department of Pharmacodynamics and Biopharmacy, University of Szeged, Eötvös $u$. 6, H-6720 Szeged, Hungary \\ ${ }^{\mathrm{f}}$ Department of Medical Physics and Informatics, University of Szeged, Korányi fasor 9, H-6720 Szeged, Hungary
}

\section{A R T I C L E I N F O}

\section{Keywords:}

Bioavailability

Loratadine

Mucoadhesive formulation

Nanosuspensions

Nasal delivery

Permeability

\begin{abstract}
A B S T R A C T
The unique requirements of poorly water-soluble drug delivery have driven a great deal of research into new formulations and routes of administration. This study investigates the use of nanosuspensions for solubility enhancement and drug delivery. Simple methods were used to prepare nasal formulations of loratadine based on nanosuspension pre-dispersion with sodium hyaluronate as a mucoadhesive agent. The nanosuspension was prepared by antisolvent precipitation method followed by ultrasonication and characterized for particle size, polydispersity index, zeta potential, morphology, and structure. Moreover, the nasal formulations were characterized for drug loading, $\mathrm{pH}$, particle size, viscosity, bioadhesive viscosity parameter, and were evaluated for in vitro dissolution and diffusion, in addition to in vivo studies in a rat model. Loratadine nanosuspension displayed a particle size of $311 \mathrm{~nm}$, a polydispersity index of 0.16 , and zeta potential of $-22.05 \mathrm{mV}$. The nanosuspension preserved the crystalline status of the raw drug. The addition of sodium hyaluronate exhibited an increase in the mean particle size and zeta potential of the nanoparticles. The nasal formulations showed enhanced bioadhesive properties compared to the unprocessed loratadine in the reference samples. The nanosuspension based-formulation that contained $5 \mathrm{mg} \mathrm{mL}^{-1}$ sodium hyaluronate and $2.5 \mathrm{mg} \mathrm{mL}^{-1}$ loratadine (NF4) showed a significant enhancement of flux and permeability coefficient through a synthetic membrane. NF4 exhibited $24.73 \mu \mathrm{g} \mathrm{cm}^{-2} \mathrm{~h}^{-1}$ and $0.082 \mathrm{~cm} \mathrm{~h}^{-1}$, while the reference sample showed $1.49 \mu \mathrm{g} \mathrm{cm}^{-2} \mathrm{~h}^{-1}$ and $0.017 \mathrm{~cm} \mathrm{~h}^{-1}$, for the flux and the permeability coefficient, respectively. Nasal administration of NF4 showed a bioavailability of 5.54-fold relative to the oral administration. The results obtained in this study indicate the potential of the nasal route and the nanosuspension for loratadine delivery. The relative bioavailability of NF4 was 1.84-fold compared to unprocessed loratadine in the reference sample. Therefore, the nanosized loratadine could be suggested as a practical and simple nanosystem for the intranasal delivery with improved bioavailability.
\end{abstract}

\section{Introduction}

The intranasal route has recently been introduced as an alternative route of administration for systemic purposes rather than the delivery of local drugs. The nasal cavity provides the advantages of large surface area, fast absorption and rapid onset of action, and avoidance of the first-pass metabolism. Besides, the nasal cavity is a safe and convenient route of administration (Illum, 2003). For the systemic effect, the drug

\footnotetext{
* Corresponding authors at: Faculty of Pharmacy, Interdisciplinary Excellence Centre, Institute of Pharmaceutical Technology and Regulatory Affairs, University of Szeged, Eötvös u. 6., H-6720 Szeged, Hungary.

E-mail addresses: areen.alshweiat@hu.edu.jo (A. Alshweiat), gaspar@med.u-szeged.hu (R. Gáspár), arita@pharm.u-szeged.hu (R. Ambrus).
} 
must be absorbed through the nasal mucosa. The absorption requires the drug to be dissolved and permeate through the mucosal tissues to reach the system circulation (Dhakar et al., 2011). Accordingly, poorly soluble or/and poorly permeable drugs must be fabricated into suitable formulations to overcome these hurdles (Costantino et al., 2007). On the other hand, the nasal cavity shows several limitations to the intranasal delivery, including short residence time, mucociliary clearance, and a limited administration volume (Grassin-Delyle et al., 2012).

Solutions to resolve the mentioned limitations include using mucoadhesive agents to reduce mucociliary clearance and high drug loading to handle the limited volume of administration (Musumeci et al., 2019; Sosnik et al., 2014). Moreover, solubility and permeability must be efficiently addressed (Ayoub et al., 2016). To enhance the mucoadhesion, many bioadhesive agents can be added such as carbomers (Bromberg, 2001), chitosans (Issa et al., 2005), thiomers (Leitner et al., 2004), alginate (Patil and Sawant, 2009), polyethylene glycol acrylate (Ugwoke et al., 2005) and Poloxamer (Dumortier et al., 2006; Fonseca et al., 2014). Sodium hyaluronate (HA) is an example of the commonly used mucoadhesive agent in nasal delivery. It extends the contact time between the formulation and the nasal mucosa, thereby contributing to drug absorption (Djupesland et al., 2014). On the other hand, HA is considered biocompatible, biodegradable, and non-immunological material (Ding et al., 2012; Lim et al., 2000).

Drugs that belong to class II of the biopharmaceutical classification system (BSC) show poor water-soluble and high permeable characteristics. Therefore, dissolution is the rate-limiting step for the absorption. Among different applied techniques, particle size reduction into the nanorange is an effective method to produce high surface area hence dissolution (Ambrus et al., 2019). Nanosuspensions is a well-known approach to produce nanoparticles. Its impacts on the dissolution of poorly water-soluble drugs have been discussed in many research studies. (Müller and Peters, 1998; Salazar et al., 2012; Yadollahi et al., 2015).

Nanosuspensions have been introduced as a solubility enhancement technique, and newly as a delivery system for many purposes (Alshweiat et al., 2019a). Intranasal delivery requires the localization of drug in the nasal cavity for sufficient time for absorption, without dripping outside the nose or running to the throat. Therefore, nanoparticles must be incorporated into mucoadhesive formulations that maintain the advantages of nanosizing simultaneously with localization inside the nasal cavity.

Various studies have reported the nasal delivery of nanosuspensions. Saindane et al. (2013) incorporated a carvedilol-containing nanosuspension into in situ gel, and Hao et al. (2016) prepared resveratrolbased nanosuspension for brain delivery. Furthermore, meloxicam nanosuspension has been introduced for systemic delivery as a powder (Kürti et al., 2013) and HA-based sprays (Bartos et al., 2015).

Loratadine (LOR) is commonly prescribed for the treatment of various allergic conditions, mostly for seasonal allergy. LOR belongs to class II of the BSC, and it is a weakly basic drug. Therefore, it exhibits a pH-dependent solubility. The oral administration of LOR is associated with variable and poor bioavailability (10-40\%) (Assanasen and Naclerio, 2002; Oppenheimer and Casale, 2002; Simons, 2002). Up to date, the nasal dosage form is not available on the market. However, various attempts were implemented to prepare LOR nasal form, such as in situ nasal gel using hydroxypropylmethylcellulose (HPMC K-100) and xanthan gum (Sherafudeen and Vasantha, 2015), $\beta$-cyclodextrin inclusion with Carbopol 943 and Poloxamer 407 (Rathnam et al., 2008), and chitosan-ethylcellulose microspheres (Martinac and Filipovi, 2005).

This study aimed to develop a nasal formulation based on nanosuspension of LOR (LNS). Size reduction could increase the dissolution rate to obtain a higher concentration of LOR and better absorption (Kocbek et al., 2006). In our previous work, the optimized process and material parameters of precipitation ultrasonic-assisted method were able to produce a pre-dispersion suitable for conversion into different dosage forms. In the present study, LOR pre-dispersions were used to prepare nasal formulations via the addition of sodium hyaluronate as a mucoadhesive agent (Alshweiat et al., 2019b, 2018). To our best knowledge, this is the first on the novel combination of nanosuspension and nasal delivery of loratadine in the literature. The developed nanosystems were straightforward and scalable.

\section{Materials and methods}

\subsection{Material}

LOR was purchased from Teva Ltd. (Budapest, Hungary). Pluronic ${ }^{\circledast}$ F68 (Poloxamer 188) was purchased from BASF (Ludwigshafen, Germany). Ethanol was supplied by Spectrum-3D (Debrecen, Hungary). $\mathrm{HA}(\mathrm{Mw}=1400 \mathrm{kDa})$ was obtained from Gedeon Richter Plc. (Budapest, Hungary). Mucin (M), porcine gastric type- II mucin, was purchased from Sigma Aldrich (Sigma Aldrich Co. LLC, St. Louis MO, US). Distilled and ultra-purified water was used (Milli-Q, Millipore GmbH, Germany).

\subsection{Methods}

In this study, simple methods were used to produce intranasal viscous-liquid formulations based on nanosuspension. The production process compromised the formulation of LOR nanosuspension and the addition of the HA to the nanosuspension. The pre-dispersion and the final formulations were characterized as follows.

\subsubsection{Preparation of LOR nanosuspension}

The Precipitation-ultrasonication method was used to prepare the LNS as a pre-dispersion (Alshweiat et al., 2018). LOR was dissolved in ethanol $\left(200 \mathrm{mg} \mathrm{mL}^{-1}\right)$ as a solvent phase, and $\mathrm{F} 68$ was dissolved in water ( $\mathrm{pH}$ 5.7) as an antisolvent phase $(0.2 \%, \mathrm{w} / \mathrm{v})$. Both solvent and antisolvent phases were filtered through a $0.45 \mu \mathrm{m}$ filter (FilterBio PES Syringe Filter, Labex Ltd., Budapest, Hungary). The solvent phase was rapidly introduced into the pre-cooled antisolvent under sonication using a UP $200 \mathrm{~s}$ Ultrasonic processor (HielscheruUltrasonics $\mathrm{GmbH}$, Germany) for $30 \mathrm{~min}$ at $4{ }^{\circ} \mathrm{C}$ and $50 \%$ amplitude. The LOR:F68 in the pre-dispersion were $2.5: 1 \mathrm{wt}$ ratio. The temperature of sonication was controlled by JulaboF32 (JULABOGmbH, Germany). LNS was stirred at room temperature for $24 \mathrm{~h}$ to remove the organic solvent.

\subsubsection{Preparation of intranasal formulations contained LOR nanocrystals}

The intranasal formulations (NFs) were prepared from the pre-dispersions by the addition of HA. The final concentrations of the formulations were controlled by dilution with $0.2 \%$, w/v F68. NFs were stored in a refrigerator at $4{ }^{\circ} \mathrm{C}$ for $24 \mathrm{~h}$ to ensure the complete solvation of the polymer. For comparison, reference samples (REF) were prepared. Table 1 shows the final concentrations of LOR and HA in the prepared nasal formulations and corresponding reference samples that contained the same amount of LOR and HA in $0.2 \%, \mathrm{w} / \mathrm{v}$ F68. However, the LOR in the reference samples was added without any processing. The REF samples were prepared by mixing raw LOR powder with HA

Table 1

Concentrations of LOR and HA (mg mL $\left.{ }^{-1}\right)$ in nasal and reference samples.

\begin{tabular}{lll}
\hline Sample & LOR $\left(\mathrm{mg} \mathrm{mL}^{-\mathbf{1}}\right)$ & HA $\left(\mathrm{mg} \mathrm{mL}^{-\mathbf{1}}\right)$ \\
\hline NF1 & 1 & 1 \\
NF2 & 1 & 5 \\
NF3 & 2.5 & 1 \\
NF4 & 2.5 & 5 \\
REF1 & 1 & 1 \\
REF2 & 1 & 5 \\
REF3 & 2.5 & 1 \\
REF4 & 2.5 & 5 \\
\hline
\end{tabular}


and $0.2 \%$ F68 solution, using ULTRA-TURRAX ${ }^{\circledR}$ homogenizer (GmbH, Germany) at $5000 \mathrm{rpm}$ for $10 \mathrm{~min}$.

\subsubsection{Evaluation of the nanosuspension}

The mean particle size (MPS), polydispersity index (PDI), and zeta potential (ZP) of LNS were measured by Malvern Nano ZS zetasizer (Malvern Instrument, UK). The samples were adequately diluted with distilled water and measured at $25{ }^{\circ} \mathrm{C}$ and $\mathrm{pH}, 5.77 .12$ parallel measurements were carried out. The samples were similarly analyzed 3 days post preparation to check the stability and the size growth of the particles.

2.2.3.1. Physicochemical characterization of the pre-dispersion. A dry sample was obtained by drying the LNS in a vacuum dryer (Binder $\mathrm{GmbH}$, Tuttlingen, Germany) at $25{ }^{\circ} \mathrm{C}$ for $24 \mathrm{~h}$ to evaluate the physicochemical properties of the nanoparticles in the pre-dispersion.

2.2.3.2. Morphology. The morphologies of LOR and the dry nanocrystal were investigated by scanning electron microscopy (SEM) (Hitachi S4700, Hitachi Scientific Ltd., Tokyo, Japan) at $10 \mathrm{kV}$. The samples were coated with gold-palladium by a sputter coater (Bio-Rad SC 502, VG Microtech, Uckfield, UK) using an electric potential of $10.0 \mathrm{kV}$ at $10 \mathrm{~mA}$.

2.2.3.3. X-ray powder diffraction (XRPD). The XRPD diffractograms of LOR and the dry nanocrystals were obtained using a BRUKER D8 Advance X-ray powder diffractometer (Bruker AXS GmbH, Karlsruhe, Germany) with $\mathrm{Cu} \mathrm{K} \lambda \mathrm{I}$ radiation $(\lambda=1.5406 \AA)$ and a VÅNTEC-1 detector. The powder samples were scanned at $40 \mathrm{kV}$ and $40 \mathrm{~mA}$, with an angular range of $3^{\circ}-40^{\circ} 2 \theta$, at a step time of $0.1 \mathrm{~s}$ and a step size of $0.01^{\circ}$.

2.2.3.4. Differential scanning calorimetry (DSC). The thermal analysis of LOR and the dry nanocrystals was carried out using a differential scanning calorimeter (Mettler Toledo DSC 821e, Mettler Inc., Schwerzenbach, Switzerland). 3-5 $\mathrm{mg}$ of the powder was accurately weighed into DSC sample pans, which were hermetically sealed and lid pierced. The samples were examined under constant argon purge in the temperature interval of $25-300{ }^{\circ} \mathrm{C}$ at a heating rate of $5{ }^{\circ} \mathrm{C} \mathrm{min}-1$.

2.2.3.5. Fourier-transform infrared spectroscopy (FT-IR). The FTIR spectra of LOR and the dry nanocrystals were obtained by Fouriertransform infrared spectroscopy (Thermo Nicolet AVATAR 330, USA) equipped with the GRAMS/AI Version seven software. Samples were compressed into pastilles with $150 \mathrm{mg}$ dry $\mathrm{KBr}$. The pastilles were scanned 128 times at a resolution of $4 \mathrm{~cm}^{-1}$ over $4000-400 \mathrm{~cm}^{-1}$ wavenumber region.

\subsubsection{Characterization of HA-based nasal formulation (NF)}

2.2.4.1. Determination of $\mathrm{pH}$. To accurately measure the $\mathrm{pH}$ of the samples, the NFs were diluted. $1 \mathrm{~mL}$ of the prepared NF was transferred into a $10 \mathrm{~mL}$ volumetric flask. The solution was diluted with distilled water (Sherafudeen and Vasantha, 2015). The $\mathrm{pH}$ of the resulting solution was determined using a digital pH meter (Inolab, pH 7116, Xylem Analytics Germany GmbH, Germany).

2.2.4.2. Determination of drug loading. $300 \mathrm{mg}$ of $\mathrm{NF}$ was dissolved in $0.1 \mathrm{~N} \mathrm{HCl}, \mathrm{pH}$ 1.2. The mixture was agitated for $24 \mathrm{~h}$ at $37 \pm 0.5{ }^{\circ} \mathrm{C}$ and filtered. The drug content was determined using a UV-visible spectrophotometer (Unicam UV/VIS) at $\lambda_{\max }$ of $248 \mathrm{~nm}$. Accordingly, the percent of drug loading was calculated from the ratio of practical and theoretical drug amount.

2.2.4.3. Rheological measurements. Rheological measurements were performed at $37{ }^{\circ} \mathrm{C}$ with a Rheostress 1 Haake instrument (Karlsruhe, Germany). A cone-plate device was used where the cone angle was $1^{\circ}$, the thickness of the sample was $0.052 \mathrm{~mm}$, and the diameter of the device was $6 \mathrm{~cm}$. The apparent viscosity curves of the samples were plotted under the shear rate range of $0.01-100 \mathrm{~s}^{-1}$.

Rheology is one of the accepted methods to characterize mucoadhesive behaviors (Hassan and Gallo, 1990). Rheological synergism between mucin and the systems can be considered as an in vitro parameter to determine the mucoadhesive behavior of systems. This viscosity change, called the bioadhesive viscosity component ( $\eta \mathrm{b})$, is caused by chemical and physical bonds formed in mucoadhesion. It can be calculated as follows:

È $b=\grave{E} t-$ È $m-$ È $p$

where $\eta_{t}$ is the viscosity of the combination of NF with mucin, $\eta_{m}$, and $\eta_{\mathrm{p}}$ are the viscosities of the mucin and NF, respectively (Hassan and Gallo, 1990).

For mucoadhesivity, NFs were stirred with mucin (M) for $3 \mathrm{~h}$ before the measurement. The final concentration of $\mathrm{M}$ in the samples was $5 \%$, $\mathrm{w} / \mathrm{w}$. The viscosity of the NFs and the combination with mucin were measured.

2.2.4.4. In vitro studies. In vitro release was carried out in a dialysis bag in artificial nasal fluid (ANF) media contained $8.77 \mathrm{mg} \mathrm{mL}^{-1} \mathrm{NaCl}$, $2.98 \mathrm{mg} \mathrm{mL}^{-1} \mathrm{KCl}$, and $0.59 \mathrm{mg} \mathrm{mL}^{-1} \mathrm{CaCl}_{2}$ at $\mathrm{pH}$ 5.6. $300 \mathrm{mg}$ of the $\mathrm{NF}$ and corresponding reference were loaded into a dialysis bag and dialyzed against $100 \mathrm{~mL}$ of the dissolution medium at $37 \pm 0.5^{\circ} \mathrm{C}$ and under $100 \mathrm{rpm}$ paddle speed. At predetermined intervals, $5 \mathrm{~mL}$ aliquots were withdrawn and replaced with an equal volume of fresh dissolution medium. The samples were filtered through a $0.45-\mu \mathrm{m}$ filter and analyzed by a UV spectrometer at $\lambda_{\max } 248 \mathrm{~nm}$.

Permeability studies were executed using a vertical Franz diffusion cell system (Logan Instrument Carporation, NJ, USA). $300 \mathrm{mg}$ of NF was placed on the polyvinylidene fluoride synthetic membrane (Durapore1 Membrane Filter, EMD Millipore, Billerica, MA, USA). The membrane was impregnated with isopropyl myristate. The actual diffusion surface was $1.72 \mathrm{~cm}^{2}$. Phosphate buffer (PBS, pH 7.4, $37^{\circ} \mathrm{C}$ ) was used as an acceptor phase $(7 \mathrm{~mL})$. The rotation of the stirring bar was set to $300 \mathrm{rpm}$. At predetermined time points of diffusion, $0.8 \mathrm{~mL}$ samples were taken from the acceptor phase by the autosampler (Hanson Microette Autosampling System, Hanson Research, Chatsworth CA, USA) and were replaced with a fresh receiving medium. The amount of LOR diffused was determined spectrophotometrically.

The flux $(\mathrm{J})$ of the drug was calculated from the quantity of LOR that permeated through the membrane, divided by the surface of the membrane insert and the duration $\left[\mathrm{mg} \mathrm{cm}^{-2} \mathrm{~h}^{-1}\right]$ using the following equation:

$\mathrm{J}=\mathrm{m} / \mathrm{At}$

The permeability coefficient $\left(\mathrm{Kp}, \mathrm{cm} \mathrm{h}^{-1}\right)$ was determined from $\mathrm{J}$, and the initial concentration of the drug in the donor phase (Cd $[\mathrm{mg}$ $\left.\mathrm{cm}^{-3}\right]$ ):

$\mathrm{Kp}[\mathrm{cm} / \mathrm{h}]=\mathrm{J} / \mathrm{Cd}$

\subsubsection{In vivo studies}

2.2.4.5.1. Drug administration in rat's model. The experimental protocols and animal care methods were approved by the National Scientific Ethical Committee on Animal Experimentation (permission number IV/1247/2017). The animals were treated following the European Communities Council Directives (2010/63/EU) and the Hungarian Act for the Protection of Animals in Research (Article 32 of Act XXVIII).

A single-dose in vivo studies were designed in male Sprague-Dawley rats weighing 220-250 g. The rats were divided into 4 groups of 4 animals each. Each rat received a dose of $0.5 \mathrm{mg} \mathrm{kg}^{-1}$ of LOR. For the first group, $50-62 \mu \mathrm{L}$ of the selected NF was administered intranasally to each rat via a $100 \mu \mathrm{L}$ pipette into the nostrils. For the second group, 
the rats were nasally given the corresponding REF sample. The rats were anesthetized using $50 \mathrm{mg} \mathrm{kg}^{-1}$ isoflurane for $5 \mathrm{~min}$ before the nasal administration.

For oral dosing, the third and fourth groups received the selected NF sample and the corresponding REF sample, respectively. However, the samples were mixed with distilled water to give the exact used dose in a proper volume for oral delivery. $1 \mathrm{~mL}$ contained $0.5 \mathrm{mg} \mathrm{kg}^{-1}$ of LOR of the samples was administered by gastric lavage.

Blood samples were collected from the tail vein. At 0.5, 1, 2, 3, 4, 8, 12 , and $24 \mathrm{~h}$ post-dose. $0.5 \mathrm{~mL}$ of blood was withdrawn into Eppendorf tubes containing sodium ethylenediaminetetraacetate. The samples were centrifuged at $1,500 \mathrm{~g}$ for $10 \mathrm{~min}$ at $5{ }^{\circ} \mathrm{C}$. Separated plasma samples were stored at $-80{ }^{\circ} \mathrm{C}$ until analysis.

2.2.4.5.2. Plasma sample preparation. LOR was isolated from plasma samples by a liquid-liquid extraction procedure. To $100 \mu \mathrm{L}$ of plasma, $10 \mu \mathrm{L}$ ACN: $\mathrm{H}_{2} \mathrm{O},(1: 1, \mathrm{v} / \mathrm{v}), 10 \mu \mathrm{L}$ of $3 \mathrm{M} \mathrm{NaOH}$, and $20 \mu \mathrm{L}$ of d5Loratadine (d5-LOR) - stable isotope-labeled internal standard (15.0 ng mL ${ }^{-1}$, in $\mathrm{ACN}: \mathrm{H}_{2} \mathrm{O}, 1: 1, \mathrm{v} / \mathrm{v}$ ) - were added. The mixture was vortexed and shaken for $10 \mathrm{~min}$ at room temperature with $1 \mathrm{~mL}$ of n-hexane on a horizontal shaker, then centrifuged for $10 \mathrm{~min}$ at $3,000 \mathrm{rpm}$ at $4{ }^{\circ} \mathrm{C}$ to obtain the clear organic layer. $800 \mu \mathrm{L}$ of the upper organic phase was transferred into a $1.5 \mathrm{~mL}$ glass vial, evaporated to dryness under a gentle stream of nitrogen and reconstituted in $100 \mu \mathrm{L}$ starting eluent $(5 \mathrm{mM}$ ammonium acetate $(\mathrm{pH}=5): \mathrm{ACN}, 6: 4, \mathrm{v} / \mathrm{v}) .20 \mu \mathrm{L}$ was injected into the LC-MS/MS system for analysis.

2.2.4.5.3. Preparation of the calibration curve. The calibration curve for the quantification of LOR was set up in drug-free rat plasma. For the preparation of standard points, $100 \mu \mathrm{L}$ rat plasma, $10 \mu \mathrm{L}$ LOR standard solution (1.8-78.4 nM, diluted in $\left.\mathrm{ACN}: \mathrm{H}_{2} \mathrm{O}, 1: 1, \mathrm{v} / \mathrm{v}\right), 10 \mu \mathrm{L} 3 \mathrm{M} \mathrm{NaOH}$, and $20 \mu \mathrm{L}$ d5-Loratadine $\left(15.0 \mathrm{ng} \mathrm{mL}{ }^{-1}\right)$ were mixed and treated as above.

2.2.4.6. $L C-M S / M S$ analysis of $L O R$. The quantitative analysis of LOR was performed by using a Waters Acquity I-Class UPLC ${ }^{\mathrm{TM}}$ system (Waters, Manchester, UK), connected to a Q Exactive ${ }^{\mathrm{TM}}$ Plus Orbitrap mass spectrometer (Thermo Fisher Scientific, San Jose, CA, USA) equipped with a heated ESI ion source (HESI-II). Chromatographic separation was performed at $25{ }^{\circ} \mathrm{C}$ column temperature, on an ACE CN column $(50 \mathrm{~mm} \times 2.1 \mathrm{~mm}$, particle size $3.0 \mu \mathrm{m})$ protected by an ACE CN guard column (Advanced Chromatography Technologies, Aberdeen, Scotland) by using $5 \mathrm{mM}$ of ammonium-acetate $(\mathrm{pH}=5)$ as Solvent A and acetonitrile as Solvent B. Gradient elution program (started and maintained at $40 \%$ B for $1 \mathrm{~min}$, increased linearly to $100 \%$ B in half $\mathrm{min}$, kept at $100 \%$ B for $1.5 \mathrm{~min}$, dropped back to $40 \% \mathrm{~B}$ in $0.1 \mathrm{~min}$ and kept there for $1.9 \mathrm{~min}$ for equilibration) with a flow rate of $300 \mu \mathrm{L} \mathrm{min}{ }^{-1}$ was applied to elute the analyte.

The mass spectrometer was used in positive mode with the following parameters of the HESI-II source: spray voltage at $3.5 \mathrm{kV}$, capillary temperature at $253{ }^{\circ} \mathrm{C}$, aux gas heater temperature at $406{ }^{\circ} \mathrm{C}$, sheath gas flow rate at 46 , aux gas flow rate at 11 , and sweep gas flow rate at 2, S-lens RF level at 50.0 (source auto-defaults). Data acquisition was performed in parallel-reaction-monitoring (PRM) mode by monitoring the transitions of $m / z 383 \rightarrow 337$ (LOR) and $m / z 388 \rightarrow 342$ (d5LOR) as quantifier and $m / z 383 \rightarrow 267$ (LOR) and $m / z 388 \rightarrow 272$ (d5LOR) as qualifier ions. The collision energy (CE) for specific quantitation was optimized to maximize sensitivity and proved to be $28 \mathrm{eV}$ for LOR and its stable isotope-labelled form, too. A valve placed after the analytical column was programmed to switch flow onto MS only when analytes of interest elute from the column (1.4-2.4 min) to prevent excessive contamination of the ion source and ion optics. Washing procedures of the autosampler before and after injecting samples were programmed to avoid carry-over of analytes.

Data acquisition and processing were carried out using Xcalibur and Quan Browser Software (Thermo Fisher Scientific, San Jose, CA, USA).
2.2.4.7. Statistical analysis and area under the curve calculation. The statistical analysis was performed with Prism 5.0 software (GraphPad, San Diego, CA). The results are shown as the mean \pm SD. The statistical methods included Student's t-test (two-group comparison). A probability $(\mathrm{P})$ of less than 0.05 was considered statistically significant $(* \mathrm{P}<0.05)$.

The calculation of area under the curve (AUC) of the time (min) concentration (nmol L ${ }^{-1}$ ) curves of each group of animals were performed with PKSolver add-in of Microsoft Excel (MS Office 2010) using non-compartmental analysis of data after extravascular input (model \#101) of LOR (Zhang et al., 2010). The AUC values were calculated using the linear trapezoidal method.

\subsubsection{Stability assessment}

Stability studies were carried out by visual inspection. Stable systems were identified to be free of any physical changes such as phase separation, flocculation, or precipitation. Stability was observed at temperatures of $4{ }^{\circ} \mathrm{C}$ and $25{ }^{\circ} \mathrm{C}$ for one month. Moreover, the formulations were evaluated for particle size, polydispersity index, zeta potential and drug content.

\section{Results and discussion}

\subsection{Characterization of nanosuspension}

The nanosuspension exhibited a MPS of $311.55 \pm 5.16 \mathrm{~nm}$, PDI of $0.16 \pm 0.024$, and $\mathrm{ZP}$ of $-22.05 \pm 2.75 \mathrm{mV}$, thus homogenous and stable nanosuspension was produced by the antisolvent precipitation assisted ultrasonication method. On the other hand, pure LOR showed aggregations in the aqueous media due to its low hydrophilic properties (Alshweiat et al., 2019b). LOR in the LNS showed saturation solubility of $8.5 \pm 0.65 \mu \mathrm{g} \mathrm{mL}^{-1}$ in PBS at $\mathrm{pH}, 5.6$. Though, pure LOR showed solubility of $1.63 \pm 0.38 \mu \mathrm{g} \mathrm{mL}{ }^{-1}$. After three days of storage, the particles of LNS showed a MPS of $319.45 \pm 4.9 \mathrm{~nm}$, PDI of $0.17 \pm 0.015$, and $\mathrm{ZP}$ of $-18.5 \pm 4.33$, respectively.

The SEM images (Fig. 1a) revealed the differences in the surface morphology between LOR and LNS. LOR showed an irregular rod-like crystal shape with aggregation. Conversely, LNS showed a uniform distribution of nanoparticles within the matrix of F68.

The DSC thermograms (Fig. 1b) depict the reduction of LOR particle size and crystallinity in LNS; LOR showed a single sharp endothermic peak at $135{ }^{\circ} \mathrm{C}$. The LNS showed a peak at $55^{\circ} \mathrm{C}$ related to $\mathrm{F} 68$ and a reduced intensity and shifted peak toward a lower melting point of LOR.

XRPD (Fig. 1c) diffractogram of LNS and LOR were similar. Therefore, the reduction of the melting point and intensity of LOR in the nanocrystals sample could be related to the particle size rather than crystallinity reduction (Murdande et al., 2015). Moreover, The FI-IR spectra showed that LNS preserved the characteristic bands of LOR, thus confirmed the compatibility between LOR and F68. The analysis details and explanations are discussed in the previous related work (Alshweiat et al., 2018).

In summary, the morphological and structural analyses have demonstrated that LOR was produced in the nano-range as a homogenous nanosuspension while it preserved the crystalline state of the drug.

\subsection{Characterization of the nasal formulations}

The prepared NFs appeared as viscous formulations. The samples showed drug content higher than $90 \%$, particularly $98.98 \pm 1.2$, $97.66 \pm 4.2,95.15 \pm 3.4$, and $92.99 \pm 2.8$ for NF1, NF2, NF3, and $\mathrm{NF} 4$, respectively. The $\mathrm{pH}$ of the samples was in the range of 6.3-6.4, hence within the acceptable range for nasal administration $(\mathrm{pH}$ of the nasal mucosa is 4.5-6.5) (England et al., 1999). LOR is unionized at these $\mathrm{pH}$ values. Therefore, dissolution enhancement is not ascribed to the salt form of LOR (Popovi et al., 2009). 

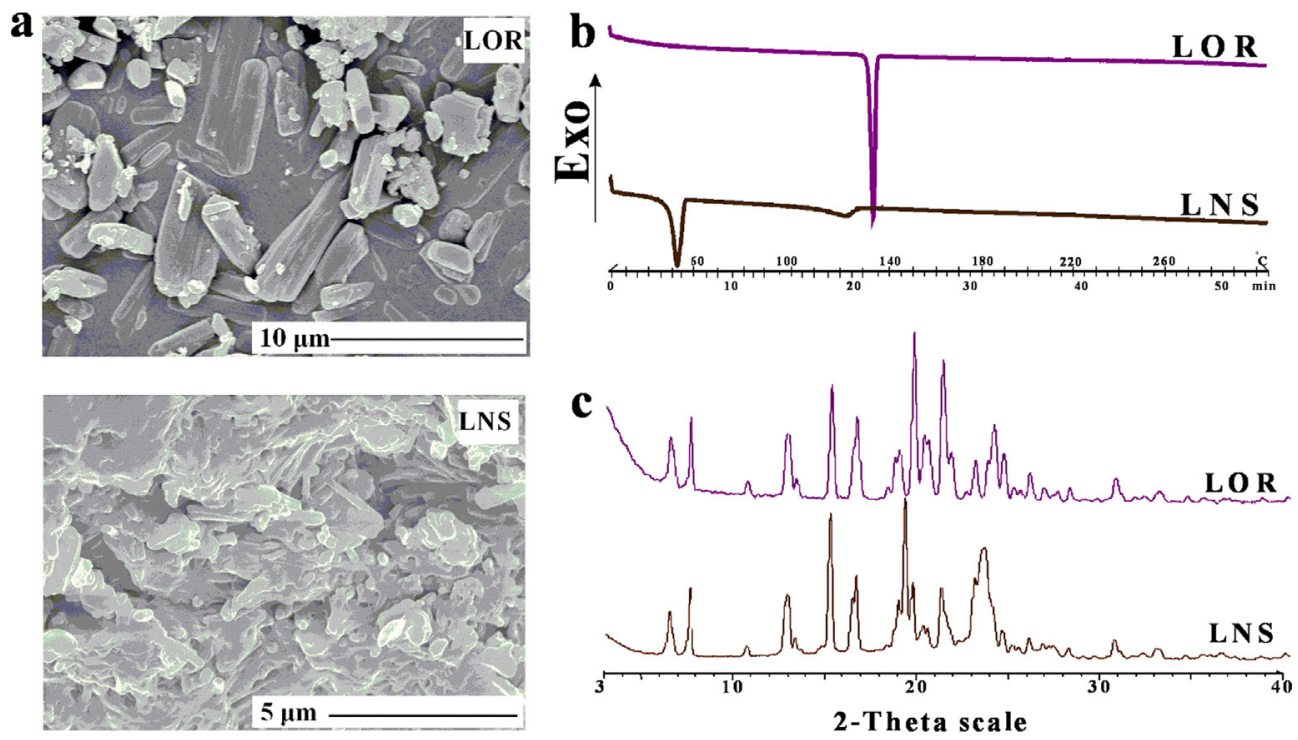

Fig. 1. Raw LOR and LOR nanocrystals characterization of (a) SEM images, (b) DSC thermograms, and (c) XRPD diffractograms. The morphological and structural analysis revealed that LOR in the nanosuspension was presented as crystalline short-rod nanocrystals.

The addition HA had significant effects on the LOR nanosuspensions in the NFs as the MPS, PDI, and ZP of the nanoparticles were increased. The MPS of LOR in NF1, NF2, NF3, and NF4 was $327.2 \pm 8.23$, $437.2 \pm 28.6,341.6 \pm 11.84$, and $450.6 \pm 24.3 \mathrm{~nm}$, respectively. Their respective PDI values were $0.249,0.314,0.254$, and 0.264 , respectively. This significant increase in particle size could be attributed to the coating of the particles by HA (Shen et al., 2015). Moreover, the presence of HA in the formulation increased the negativity charge. The $\mathrm{ZP}$ values were $-55.1 \pm 5.67,-50.3 \pm 3 \pm 6.68,-45.9 \pm 6.36$, and $-52.2 \pm 6.91 \mathrm{mV}$ for NF1, NF2, NF3, and NF4, respectively (Sharma et al., 2016; Shen et al., 2015).

\subsection{Rheological properties of NFs}

The NFs showed a shear thinning-flow (pseudoplastic). The viscosity curve (Fig. 2) displayed a decreasing slope, that is typical for sodium hyaluronate solutions (Krause et al., 2001). The rheological behaviors of the NFs were similar to the corresponding blank solutions that contained $1 \mathrm{mg} \mathrm{mL}^{-1}$ and $5 \mathrm{mg} \mathrm{mL}^{-1}$ of $\mathrm{HA}$ in $0.2 \% \mathrm{w} / \mathrm{v} \mathrm{F} 68$ noted as blank1 and blank5, respectively. However, the reduced particle size of LOR showed higher viscosity than the blank samples. Therefore, the nanosized LOR improved the viscosity of blank solutions. Comparable outcomes are reported by the work of Bartos et al. (2015).

\subsection{Mucoadhesion of the nasal formulations}

Samples with and without mucin were prepared to evaluate the role of LOR nanosuspension in mucoadhesion. The bioadhesive viscosity component, synergism parameter, was calculated from the average viscosity values.

The systems of NFs and 5\% mucin (NF-M) showed shear-thinning behaviors. The viscosity of the NF-M systems was higher than the corresponding NF (Suppl Fig. 1) due to the polymer or mucin entanglement, and interactions between the polymer and mucin via the hydrogen bonds (Thirawong et al., 2008).

The synergism parameters $\left(\mathrm{n}_{\mathrm{b}}\right)$ of the NFs were compared to the F68 solution, corresponding REF samples, and the corresponding blanks (Fig. 3). The blanks showed mucoadhesive properties depending on the concentration of the sodium hyaluronate. The values of the bioadhesive viscosity were 0.6 and $46.5 \mathrm{mPa} * \mathrm{~s}$ for blank 1 and blank5, respectively. The negative values $\eta_{b}$ of REF1 and REF3 could be related to the insufficient amount of HA to interact with the mucin. The addition of the LNS to the blanks increased the mucoadhesivity of the formulations. This effect could be related to the interactions between the mucin and the dispersed nanosized LOR particles.

The synergism effect was directly linked to the HA and nanosized drug amount. These outcomes could be related to a higher interaction

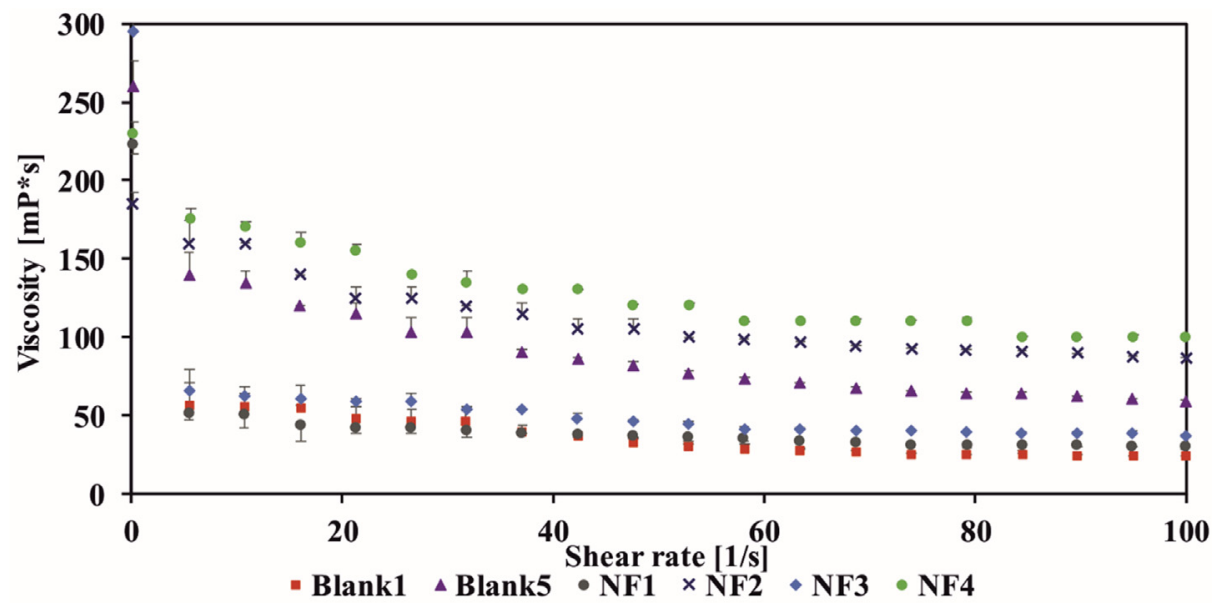

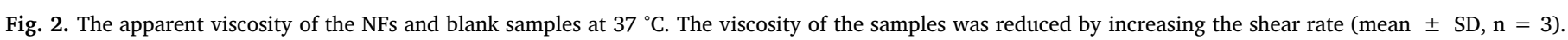




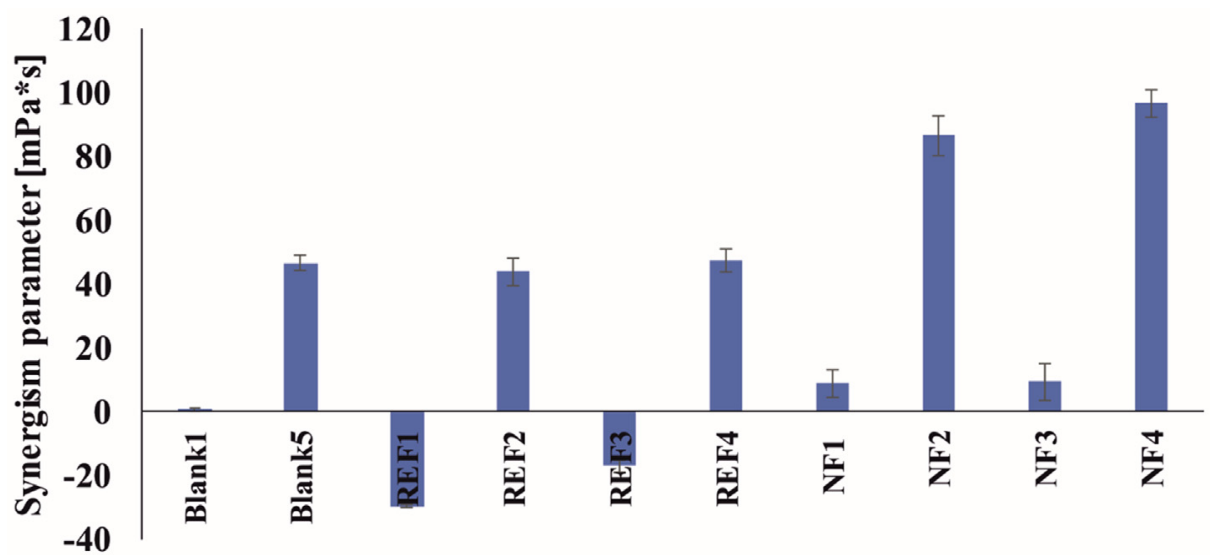

Fig. 3. Calculated synergism parameters at a shear rate of $100 \mathrm{~s}^{-1}$ and $37{ }^{\circ} \mathrm{C}$. The nanosized formulation showed higher viscosity parameter than the corresponding REF samples and blank solutions (mean $\pm \mathrm{SD}, \mathrm{n}=3$ ).

of the HA with the mucin and the nanocrystals. Accordingly, NF4 showed the highest synergism parameter. The $\eta \mathrm{b}$ was 2.8 -fold compared to blank5. The nanosized LOR was in the size of polymeric molecules of HA and mucin chains, hence better interaction among the components and higher mucoadhesivity could be obtained (Horvát et al., 2009).

NF4 that showed the highest mucoadhesive parameter. Therefore, it was selected for further studies.

\subsection{Effects of nanosizing on the diffusion and permeability of LOR}

LOR shows a poor water solubility. Thus, many studies suggested the use of $900 \mathrm{~mL}$ of dissolution media or/and the addition of surfactant or co-solvent in the dissolution media to fulfill sink conditions (Damian et al., 2016; Song and Shin, 2009; Vlaia et al., 2017). In this study, the sink conditions were not applied due to factors related to the limited volume of the nasal delivery, lack of surfactant on the nasal cavity to be simulated by the dissolution media and to evaluate the effect of the particle size reduction on dissolution and diffusion without any interventions from the surfactant. Moreover, NF4 solubility in the ANF was $6.43 \pm 1.68 \mu \mathrm{g} \mathrm{mL}^{-1}$. Therefore, and based on LOR content in the NF4, the sink conditions were not fulfilled. NF4 formulation was compared to REF4. NF4 showed an enhanced drug release compared to the reference sample (Fig. 4). Approximately $77 \%$ of the drug was released from NF4 within the first 15 min compared to $10 \%$ from the reference sample. These discrepancies in dissolution rates could be related to the nanosizing effects, as small particles produced a higher surface area than the microparticles. Thus, dissolution according to the Noys-Whitney equation. Moreover, the nanosizing of LOR showed a 5.2-fold saturation solubility compared to the raw drug (Agrawal and Patel, 2011).

The diffusion indicates the permeation property. In this study, the membrane pore size was $100 \mathrm{~nm}$, so LOR particles were unable to pass directly through the membrane. Consequently, the high surface area achieved by the nanosized particles was the main factor affecting the rate of passive diffusion.

The diffusion from NF4 was faster than REF4 due to the higher dissolution of the drug (Fig. 5). LOR diffused immediately from NF4 while is diffused after $10 \mathrm{~min}$ from the REF4. The flux $(\mathrm{J})$ represents the amount of LOR permeated through a $1 \mathrm{~cm}^{2}$ of the membrane within $1 \mathrm{~h}$. NF4 that contained LOR nanoparticles showed a significantly increased $\mathrm{J}$ compared to REF4 $\left(24.73 \pm 3.2\right.$ and $1.49 \pm 1.03 \mu \mathrm{g} \mathrm{cm}{ }^{-2} \mathrm{~h}^{-1}$, respectively). Therefore, HA containing-formulations allowed the penetration of LOR through the synthetic membrane. However, the flux of the nanosized-based formulation was higher than the reference sample containing the raw LOR. The permeability coefficient (Kp) of NF4 also showed a higher value than REF4. Kp values were 0.082 and $0.017 \mathrm{~cm} \mathrm{~h}^{-1}$, respectively. In particular, $11.15 \mu \mathrm{g} \mathrm{cm}{ }^{-2}$ of the drug diffused in the first $15 \mathrm{~min}$ from the NF4 compared to $0.56 \mu \mathrm{g} \mathrm{cm}^{-2}$ form the REF4. The higher diffusion could be connected to the higher

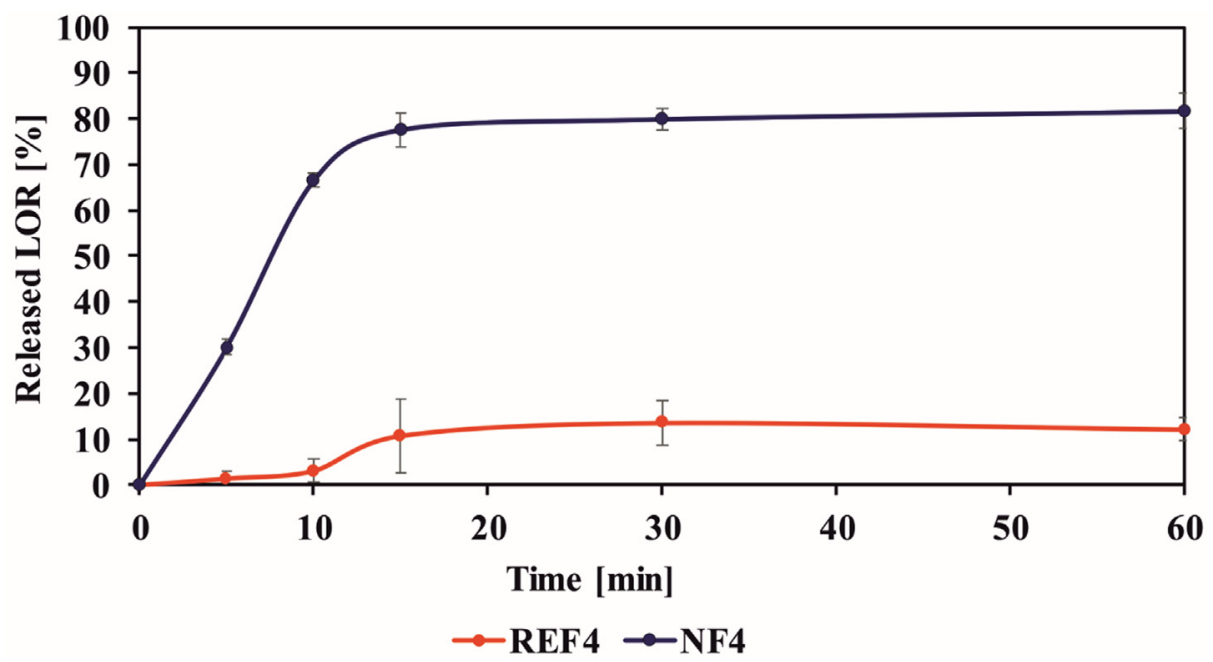

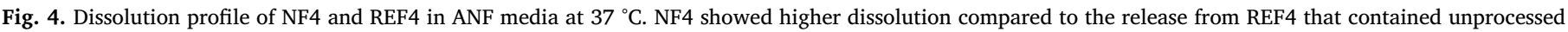
LOR (mean $\pm \mathrm{SD}, \mathrm{n}=3$ ). 


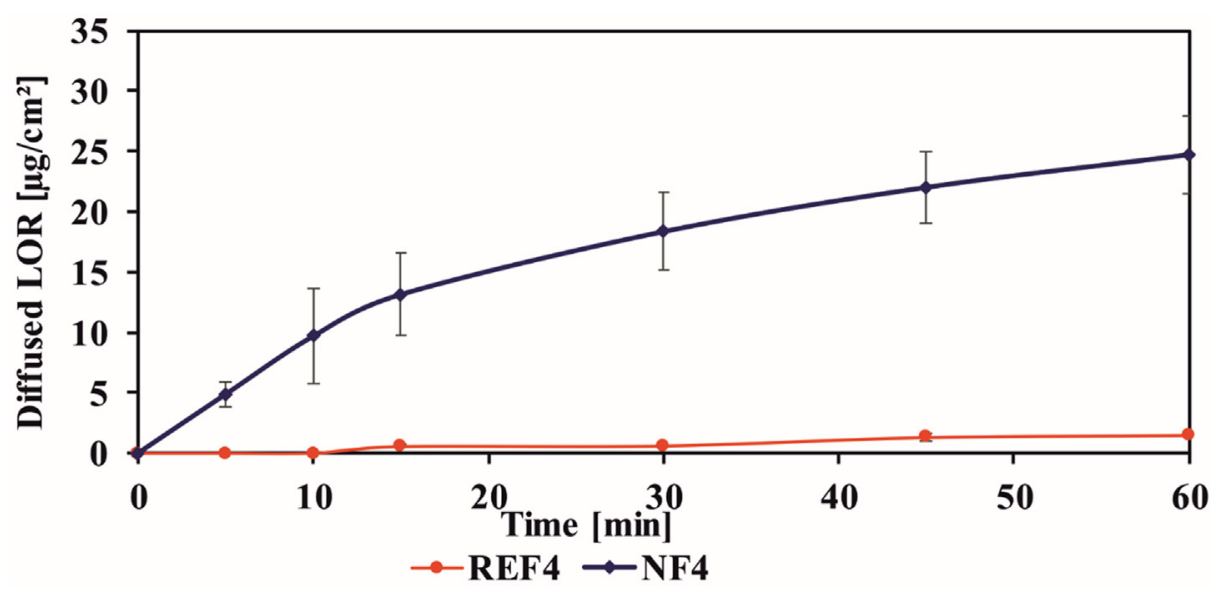

Fig. 5. In vitro permeability of NF4 and REF4 through a synthetic membrane using a Franz-diffusion cell at $37^{\circ} \mathrm{C}$. NF4 showed a higher flux and permeability of LOR than REF4 (mean $\pm \mathrm{SD}, \mathrm{n}=3$ ).

surface area produced by the nanoparticles. The viscosity of the NF4 was at a low level (Section 3.3) that is suitable for nasal spray (Bartos et al., 2018).

\subsection{In vivo studies}

Nanosuspension based LOR was designed to improve the drug bioavailability by the intranasal route. Plasma levels after intranasal administration of the nanoparticle formulations were compared with those achieved with a reference sample that contained unprocessed suspended LOR (REF4). Moreover, nasal delivery was compared to the oral one. Fig. 6 shows the mean LOR plasma concentration-time profiles after intranasal and oral delivery of NF4 and REF4.

As stated previously, LOR belongs to class II of the BCS. Thus it shows good permeability. $\mathrm{C}_{\max }$ after the nasal administration is significantly higher than the oral administration $(\mathrm{P} \leq 0.01)$. The $\mathrm{C}_{\max }$ was $6.388,13.29$, 38.357, and $39.991 \mathrm{nM}$ for REF4-oral, NF4-oral, REF4nasal, and NF4-nasal, respectively (Table 2). The higher nasal concentrations could be related to higher absorption through the high vascularized mucosa and bypassing the first-pass metabolism. Moreover, HA could act as a permeation enhancer for LOR through the nasal mucosa (Illum et al., 1994). Apart from this, the plasma concentration of REF4-oral, REF4-nasal, and NF4-oral decreased after $12 \mathrm{~h}$. However, NF4-nasal plasma concentration was $3.85 \mathrm{nmol} \mathrm{L}^{-1}$ and still detected to $24 \mathrm{~h}$ resulting in lower $\mathrm{k}_{\mathrm{e}}$.

The mucoadhesive properties for the nanosuspension in NF4 were visible as mucoadhesion would improve the drug absorption and could prolong the intimate contact time of the particle on the nasal mucosa by adhering to the surface of the mucus layer. Therefore, NF4 showed extended and elevated plasma concentration of LOR than REF4, considering the exclusion of the mucoadhesive agent consequences as the samples contained the same concentrations of HA (Morimoto et al., 1991). Fig. 7 shows the AUC $_{0-\infty}$ values (Table 2) for LOR after oral and nasal administration. The relative bioavailability of the intranasal delivered NF4 was 1.84-fold compared to the REF4 and 5.54-fold compared to the oral delivered sample i.e. NF4-oral.

These findings provide evidence that nasal administration enhanced the bioavailability of LOR. Moreover, the nanoparticles are practical to improve the delivery of LOR through the nasal route.

\subsection{Stability}

There was no significant change in terms of physical appearance and viscosity. Furthermore, no particle precipitation occurred over one month for the samples kept at $4{ }^{\circ} \mathrm{C}$. Though, the samples at $25{ }^{\circ} \mathrm{C}$ showed precipitation and phase separation. Thus, the storage of formulations would be more appropriate at refrigerated conditions to ensure the stability of the products. The drug content of NF4 samples after the storage period at $4{ }^{\circ} \mathrm{C}$ was $89.48 \pm 3.6 \%$.

The mean particle size of LOR nanoparticles in NF4 was $395.1 \pm 11.13$. Moreover, the NF4 showed a PDI of $0.35 \pm 0.02$ and ZP of $-39.4 \pm 6.84$. The stability of the formulation could be related to

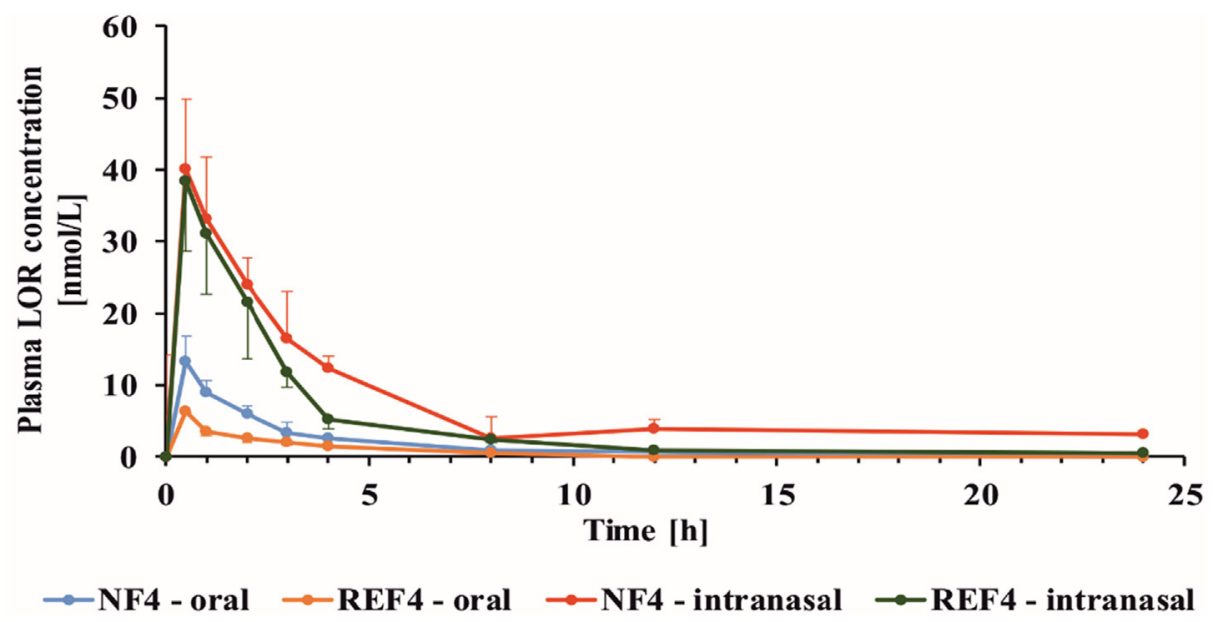

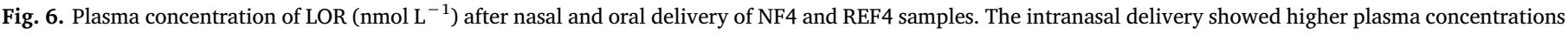
than oral administration and the nanosuspension based formulation showed higher plasma concentration than REF4 (mean \pm SD, $\mathrm{n}=4$ ). 
Table 2

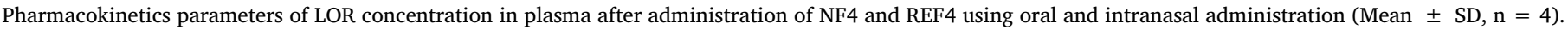

\begin{tabular}{|c|c|c|c|c|}
\hline & \multicolumn{2}{|l|}{ Oral } & \multicolumn{2}{|l|}{ Intranasal } \\
\hline & NF4 & REF4 & NF4 & REF4 \\
\hline$k_{e}\left[h^{-1}\right]$ & $0.240 \pm 0.036$ & $0.238 \pm 0.034$ & $0.115 \pm 0.013$ & $0.236 \pm 0.085$ \\
\hline $\mathrm{C}_{\max }[\mathrm{nM}]$ & $13.29 \pm 5.716$ & $6.388 \pm 2.205$ & $39.991 \pm 14.180$ & $38.357 \pm 9.778$ \\
\hline $\mathrm{AUC}_{0-\infty}\left[\mathrm{h} \mathrm{nmol} \mathrm{L}^{-1}\right]$ & $36.588 \pm 9.785$ & $17.812 \pm 1.962$ & $202.708 \pm 43.311$ & $110.353 \pm 10.414$ \\
\hline
\end{tabular}

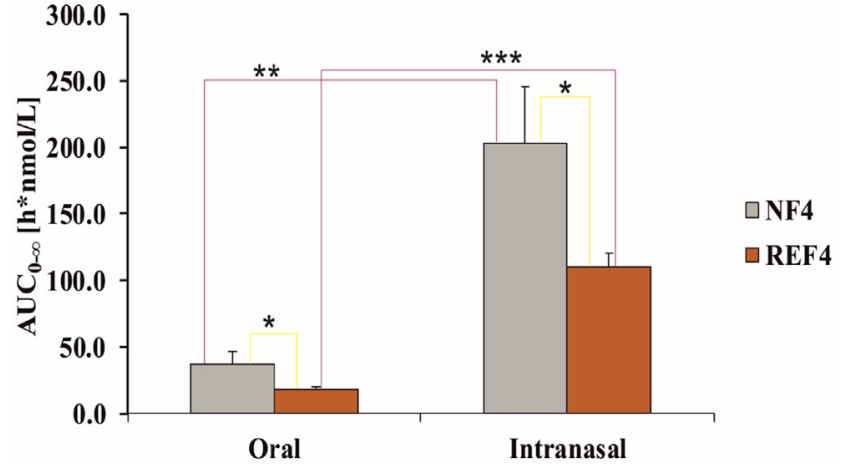

Fig. 7. AUC $0_{-\infty}\left(\mathrm{h} \mathrm{nmol} \mathrm{L}^{-1}\right)$ of plasma after nasal and oral administration of NF4 and REF4. The nasal delivery NF4 showed an improved bioavailability compared to the REF4 and to oral administration ( $*, \mathrm{P}=0.02 ; * *, \mathrm{P}=0.003$, $* * *, P=0.0003)($ mean $\pm S D, n=4)$.

the high zeta potential and the viscosity of the formulation that kept the LOR nanoparticles separated and homogeneously distributed through the matrix (Müller and Jacobs, 2002). Moreover, the reduction of particle size after 1-month storage compared to the fresh samples could be related to the drug-stabilizer interactions (Md et al., 2018).

\section{Conclusions}

Simple methods of preparation were used to develop loratadine nasal formulation. The combination of nanosuspension and simple addition of a mucoadhesive agent presented a promising platform for the nasal delivery of loratadine. The crystalline state of LOR was not altered through nanosizing by the ultrasonication method. Thus, long-term time stability of formulations could be improved. The reduction of particle size presented enhanced mucoadhesive properties. Moreover, using a mucoadhesive agent is crucial to extend the contact time between the formulation and nasal mucosa. The parameters of polymer concentration, drug concentration, and interaction with mucin were studied. More precisely, NF4 formulation that contained $2.5 \mathrm{mg} \mathrm{mL}^{-1}$ of loratadine and $5 \mathrm{mg} \mathrm{mL} \mathrm{m}^{-1}$ sodium hyaluronate showed enhanced rheological behaviors as presented by the synergism parameter where nanosizing had the main effect in the higher mucoadhesivity. Moreover, NF4 showed enhanced dissolution in an artificial nasal fluid. Besides, higher diffusion and permeability coefficient compared to the unprocessed loratadine. The evidence from the in vivo studies showed the superiority of nasal delivery over the oral administration.

\section{CRediT authorship contribution statement}

Areen Alshweiat: Conceptualization, Methodology, Investigation, Formal analysis. IIdikó Csóka: Supervision. Ferenc Tömösi: Methodology. Tamás Janáky: Supervision. Anita Kovács: Investigation. Róbert Gáspár: Data curation. Anita Sztojkov-Ivanov: Investigation. Eszter Ducza: Methodology. Árpád Márki: Data curation. Piroska Szabó-Révész: Supervision. Rita Ambrus: Supervision, Project administration, Resources, Writing - review \& editing.

\section{Declaration of Competing Interest}

The authors declare that they have no known competing financial interests or personal relationships that could have appeared to influence the work reported in this paper.

\section{Acknowledgments}

This work was supported by Gedeon Richter Ltd - GINOP project (2.2.1-15-2016-00007), Ministry of Human Capacities, Hungary grant 20391-3/2018/FEKUSTRAT and TUDFO/47138-1/2019-ITM project is also acknowledged.

\section{Appendix A. Supplementary material}

Supplementary data to this article can be found online at https:// doi.org/10.1016/j.ijpharm.2020.119166.

\section{References}

Agrawal, Y., Patel, V., 2011. Nanosuspension: An approach to enhance solubility of drugs. J. Adv. Pharm. Technol. Res. 2, 81. https://doi.org/10.4103/2231-4040.82950.

Alshweiat, A., Ambrus, R., Csoka, I., 2019a. Intranasal nanoparticulate systems as alternative route of drug delivery. Curr. Med. Chem. 26, 6459-6492. https://doi.org/10. 2174/0929867326666190827151741.

Alshweiat, A., Ambrus, R., Katona, G., Csoka, Ii, 2019b. QbD based control strategy of loratadine nanosuspensions and dry nanoparticles stabilized by soluplus ${ }^{\oplus}$. Farmacia 67, 729-735. https://doi.org/10.31925/farmacia.2019.4.23.

Alshweiat, A., Katona, G., Csóka, I., Ambrus, R., 2018. Design and characterization of loratadine nanosuspension prepared by ultrasonic-assisted precipitation. Eur. J. Pharm. Sci. 122, 94-104. https://doi.org/10.1016/j.ejps.2018.06.010.

Ambrus, R., Alshweiat, A., Csóka, I., Ovari, G., Esmail, A., Radacsi, N., 2019. 3D-printed electrospinning setup for the preparation of loratadine nanofibers with enhanced physicochemical properties. 118455. Int. J. Pharm. 567. https://doi.org/10.1016/j. ijpharm. 2019. 118455.

Assanasen, P., Naclerio, R.M., 2002. Antiallergic anti-inflammatory effects of H1-antihistamines in humans. Clin. Allergy Immunol. 17, 101-139.

Ayoub, A.M., Ibrahim, M.M., Abdallah, M.H., Mahdy, M.A., 2016. Sulpiride microemulsions as antipsychotic nasal drug delivery systems: In-vitro and pharmacodynamic study. J. Drug Deliv. Sci. Technol. 36, 10-22. https://doi.org/10.1016/j.jddst.2016. 09.002 .

Bartos, C., Ambrus, R., Kovács, A., Gáspár, R., Sztojkov-Ivanov, A., Márki, Á., Janáky, T., Tmsi, F., Kecskeméti, G., Szabó-Révész, P., 2018. Investigation of absorption routes of meloxicam and its salt form from intranasal delivery systems. Molecules 23, 1-13. https://doi.org/10.3390/molecules23040784.

Bartos, C., Ambrus, R., Sipos, P., Budai-Szucs, M., Csányi, E., Gáspár, R., Márki, Á., Seres, A.B., Sztojkov-Ivanov, A., Horváth, T., Szabó-Révész, P., 2015. Study of sodium hyaluronate-based intranasal formulations containing micro- or nanosized meloxicam particles. Int. J. Pharm. 491, 198-207. https://doi.org/10.1016/j.ijpharm. 2015.06.046.

Bromberg, L.E., 2001. Enhanced nasal retention of hydrophobically modified polyelectrolytes. J. Pharm. Pharmacol. 53, 109-114. https://doi.org/10.1211/ 0022357011775082.

Costantino, H.R., Illum, L., Brandt, G., Johnson, P.H., Quay, S.C., 2007. Intranasal delivery: Physicochemical and therapeutic aspects. Int. J. Pharm. 337, 1-24. https:// doi.org/10.1016/j.ijpharm.2007.03.025.

Damian, F., Harati, M., Pathak, V., Schwartzenhauer, J., Durham, D., Quiquero, V., Van Cauwenberghe, O., Wettig, S.D., 2016. Development of a discriminating dissolution method for immediate-release soft gelatin capsules containing a BCS class II compound. Dissolution Technol. 23, 6-13. https://doi.org/10.14227/DT230416P6.

Dhakar, R.C., Maurya, S.D., Tilak, V.K., Gupta, A.K., 2011. A review on factors affecting the design of nasal drug delivery system. Int. J. Drug Deliv. 1, 194-208.

Ding, J., He, R., Zhou, G., Tang, C., Yin, C., 2012. Multilayered mucoadhesive hydrogel films based on thiolated hyaluronic acid and polyvinylalcohol for insulin delivery. Acta Biomater. 8, 3643-3651. https://doi.org/10.1016/j.actbio.2012.06.027.

Djupesland, P.G., Messina, J.C., Mahmoud, R.A., 2014. Therapeutic Delivery 5, 709-733. Dumortier, G., Grossiord, J.L., Agnely, F., Chaumeil, J.C., 2006. A review of poloxamer 
407 pharmaceutical and pharmacological characteristics. Pharm. Res. 23, 2709-2728. https://doi.org/10.1007/s11095-006-9104-4.

England, R.J.A., Homer, J.J., Knight, L.C., Ell, S.R., 1999. Nasal pH measurement: A reliable and repeatable parameter. Clin. Otolaryngol. Allied Sci. 24, 67-68. https://do org/10.1046/j.1365-2273.1999.00223.x.

Fonseca, F.N., Betti, A.H., Carvalho, F.C., Gremião, M.P.D., Dimer, F.A., Guterres, S.S., Tebaldi, M.L., Rates, S.M.K., Pohlmann, A.R., 2014. Mucoadhesive amphiphilic methacrylic copolymer-functionalized poly( $\varepsilon$-caprolactone) nanocapsules for nose-tobrain delivery of olanzapine. J. Biomed. Nanotechnol. 11, 1472-1481. https://doi. org/10.1166/jbn.2015.2078.

Grassin-Delyle, S., Buenestado, A., Naline, E., Faisy, C., Blouquit-Laye, S., Couderc, L.J., Le Guen, M., Fischler, M., Devillier, P., 2012. Intranasal drug delivery: An efficient and non-invasive route for systemic administration - Focus on opioids. Pharmacol. Ther. 134, 366-379. https://doi.org/10.1016/j.pharmthera.2012.03.003.

Hao, J., Zhao, J., Zhang, S., Tong, T., Zhuang, Q., Jin, K., Chen, W., Tang, H., 2016. Fabrication of an ionic-sensitive in situ gel loaded with resveratrol nanosuspensions intended for direct nose-to-brain delivery. Colloids Surf., B: Biointerfaces. 147, 376-386. https://doi.org/10.1016/j.colsurfb.2016.08.011.

Hassan, E.E., Gallo, J.M., 1990. A simple rheological method for the in vitro assessment of mucin-polymer bioadhesive bond strength. Pharm. Res.: Pharm. Res. 7, 491-495. https://doi.org/10.1023/A:1015812615635.

Horvát, S., Fehér, A., Wolburg, H., Sipos, P., Veszelka, S., Tóth, A., Kis, L., Kurunczi, A., Balogh, G., Kürti, L., Eros, I., Szabó-Révész, P., Deli, M.A., 2009. Sodium hyaluronate as a mucoadhesive component in nasal formulation enhances delivery of molecules to brain tissue. Eur. J. Pharm. Biopharm. 72, 252-259. https://doi.org/10.1016/j.ejpb. 2008.10.009.

Illum, L., 2003. Nasal drug delivery - possibilities, problems and solutions. J. Control. Release. 7, 187-198. https://doi.org/10.1016/S0168-3659(02)00363-2.

Illum, L., Farraj, N.F., Fisher, A.N., Gill, I., Miglietta, M., Benedetti, L.M., 1994. Hyaluronic acid ester microspheres as a nasal delivery system for insulin. J. Control. Release. 29, 133-141. https://doi.org/10.1016/0168-3659(94)90129-5.

Issa, M.M., Köping-Höggård, M., Artursson, P., 2005. Chitosan and the mucosal delivery of biotechnology drugs. Drug Discov. Today Technol. 2, 1-6. https://doi.org/10 1016/j.ddtec.2005.05.008.

Kocbek, P., Baumgartner, S., Kristl, J., 2006. Preparation and evaluation of nanosuspensions for enhancing the dissolution of poorly soluble drugs. Int. J. Pharm. 312, 179-186. https://doi.org/10.1016/j.ijpharm.2006.01.008.

Krause, W.E., Bellomo, E.G., Colby, R.H., 2001. Rheology of sodium hyaluronate under physiological conditions. Biomacromolecules 2, 65-69. https://doi.org/10.1021/ bm0055798.

Kürti, L., Gáspár, R., Márki, Á., Kápolna, E., Bocsik, A., Veszelka, S., Bartos, C., Ambrus, R., Vastag, M., Deli, M.A., Szabó-Révész, P., 2013. In vitro and in vivo characterization of meloxicam nanoparticles designed for nasal administration. Eur. J. Pharm. 50, 86-92. https://doi.org/10.1016/j.ejps.2013.03.012.

Leitner, V.M., Guggi, D., Krauland, A.H., Bernkop-Schnärch, A., 2004. Nasal delivery of human growth hormone: In vitro and in vivo evaluation of a thiomer/glutathione microparticulate delivery system. J. Control. Release. 100, 87-95. https://doi.org/ 10.1016/j.jconrel.2004.08.001.

Lim, S.T., Martin, G.P., Berry, D.J., Brown, M.B., 2000. Preparation and evaluation of the in vitro drug release properties and mucoadhesion of novel microspheres of hyaluronic acid and chitosan. J. Control. Release. 66, 281-292. https://doi.org/10.1016/ S0168-3659(99)00285-0.

Martinac, A., Filipovi, J., 2005. Development and bioadhesive properties of chitosanethylcellulose microspheres for nasal delivery. Int. J. Pharm. 291, 69-77. https://doi. org/10.1016/j.ijpharm.2004.07.044

Md, S., Kit, B.C.M., Jagdish, S., David, D.J.P., Pandey, M., Chatterjee, L.A., 2018. Development and in vitro evaluation of a zerumbone loaded nanosuspension drug delivery system. Crystals 8, 1-13. https://doi.org/10.3390/cryst8070286.

Morimoto, K., Yamaguchi, H., Iwakura, Y., Morisaka, K., Ohashi, Y., Nakai, Y., 1991. Effects of viscous hyaluronate-sodium solutions on the nasal absorption of vasopressin and an analogue. Pharm. Res. 8, 471-474. https://doi.org/10.1023/ a:1015894910416.

Müller, R.H., Jacobs, C., 2002. Buparvaquone mucoadhesive nanosuspension: preparation, optimisation and long-term stability. Int. J. Pharm. 237, 151-161. https://doi
org/10.1016/S0378-5173(02)00040-6

Müller, R.H., Peters, K., 1998. Nanosuspensions for the formulation of poorly soluble drugs. I. Preparation by a size-reduction technique. Int. J. Pharm. 160, 229-237. https://doi.org/10.1016/S0378-5173(97)00311-6.

Murdande, S.B., Shah, D.A., Dave, R.H., 2015. Impact of nanosizing on solubility and dissolution rate of poorly soluble impact of nanosizing on solubility and dissolution rate of poorly. J. Pharm. Sci. 104, 2094-2102. https://doi.org/10.1002/jps.24426.

Musumeci, T., Bonaccorso, A., Puglisi, G., 2019. Epilepsy disease and nose-to-brain delivery of polymeric nanoparticles: an overview. Pharmaceutics 11, 118. https://doi. org/10.3390/pharmaceutics11030118.

Oppenheimer, J.J., Casale, T.B., 2002. Next generation antihistamines: therapeutic rationale, accomplishments and advances. Expert Opin. Investig. Drugs. 11, 807-817. https://doi.org/10.1517/13543784.11.6.807.

Patil, S.B., Sawant, K.K., 2009. Development, optimization and in vitro evaluation of alginate mucoadhesive microspheres of carvedilol for nasal delivery. J. Microencapsul. 26, 432-443. https://doi.org/10.1080/02652040802456726.

Popovi, G., `Cakar, M., Agbaba, D., 2009. Acid - base equilibria and solubility of loratadine and desloratadine in water and micellar media. J. Pharm. Biomed. Anal. 49, 42-47. https://doi.org/10.1016/j.jpba.2008.09.043.

Rathnam, G., Narayanan, N., Ilavarasan, R., 2008. Carbopol-based gels for nasal delivery of progesterone. AAPS. PharmSciTech. 9, 1078-1082. https://doi.org/10.1208/ s12249-008-9144-7.

Saindane, N.S., Pagar, K.P., Vavia, P.R., 2013. Nanosuspension based in situ gelling nasal spray of carvedilol: development, in vitro and in vivo characterization. AAPS PharmSciTech. 14, 189-199. https://doi.org/10.1208/s12249-012-9896-y.

Salazar, J., Ghanem, A., Müller, R.H., Möschwitzer, J.P., 2012. Nanocrystals: Comparison of the size reduction effectiveness of a novel combinative method with conventional top-down approaches. Eur. J. Pharm. Biopharm. 81, 82-90. https://doi.org/10.1016/ j.ejpb.2011.12.015.

Sharma, S., Singh, J., Verma, A., Teja, B.V., Shukla, R.P., Singh, S.K., Sharma, V., Konwar, R., Mishra, P.R., 2016. Hyaluronic acid anchored paclitaxel nanocrystals improves chemotherapeutic efficacy and inhibits lung metastasis in tumor-bearing rat model. RSC Adv. 6, 73083-73095. https://doi.org/10.1039/C6RA11260A.

Shen, H., Shi, S., Zhang, Z., Gong, T., Sun, X., 2015. Coating solid lipid nanoparticles with hyaluronic acid enhances antitumor activity against melanoma stem-like cells. Theranostics 5, 755-771. https://doi.org/10.7150/thno.10804.

Sherafudeen, S.P., Vasantha, P.V., 2015. Development and evaluation of in situ nasal gel formulations of loratadine. Res. Pharm. Sci. 10, 466-476.

Simons, F.E.R., 2002. Comparative pharmacology of H1 antihistamines: clinical relevance. N. Engl. J. Med. 113 (Suppl), 38S-46S. https://doi.org/10.1016/S00029343(02)01436-5.

Song, J.H., Shin, S.C., 2009. Development of the loratadine gel for enhanced transdermal delivery. Drug Dev. Ind. Pharm. 35, 897-903. https://doi.org/10.1080/ 03639040802680289.

Sosnik, A., Das Neves, J., Sarmento, B., 2014. Mucoadhesive polymers in the design of nano-drug delivery systems for administration by non-parenteral routes: A review. Prog. Polym. Sci. 39, 2030-2075. https://doi.org/10.1016/j.progpolymsci.2014.07. 010.

Thirawong, N., Kennedy, R.A., Sriamornsak, P., 2008. Viscometric study of pectin-mucin interaction and its mucoadhesive bond strength. Carbohydr. Polym. 71, 170-179. https://doi.org/10.1016/j.carbpol.2007.05.026.

Ugwoke, M.I., Agu, R.U., Verbeke, N., Kinget, R., 2005. Nasal mucoadhesive drug delivery: Background, applications, trends and future perspectives. Adv. Drug Deliv. Rev. 57, 1640-1665. https://doi.org/10.1016/j.addr.2005.07.009.

Vlaia, L., Coneac, G., Olariu, I., Lupuliasa, T., Dan, A.M., Maxim, M.E., Saramet, G., Mitu, M., Lupuliasa, D., Vlaia, V., 2017. Loratadine-loaded microemulsions for topical application. Formulation, physicochemical characterization and in vitro drug release evaluation. Farmacia 65, 851-861.

Yadollahi, R., Vasilev, K., Simovic, S., 2015. Nanosuspension technologies for delivery of poorly soluble drugs - A review. J. Nanomater. 15, 1-13. https://doi.org/10.1155/ 2015/216375.

Zhang, Y., Huo, M., Zhou, J., Xie, S., 2010. PKSolver: An add-in program for pharmacokinetic and pharmacodynamic data analysis in Microsoft Excel. Comput. Methods. Programs. Biomed. 99, 306-314. https://doi.org/10.1016/j.cmpb.2010.01.007. 